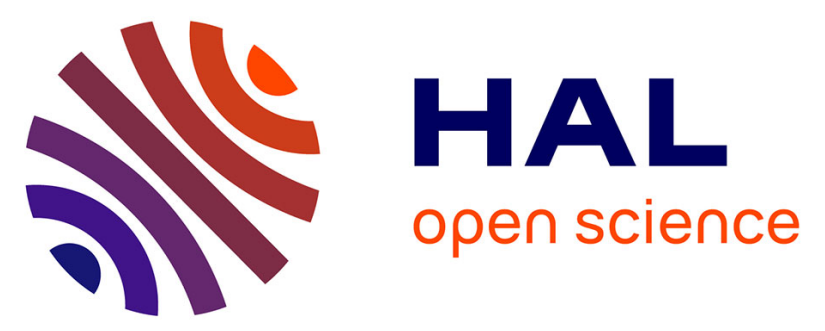

\title{
Subjective memory impairment, objective cognitive functioning and social activity in French older people: findings from the Three Cities study.
}

Mirella Genziani, Robert Stewart, Yannick Béjot, Hélène Amieva, Sylvaine Artero, Karen Ritchie

\section{To cite this version:}

Mirella Genziani, Robert Stewart, Yannick Béjot, Hélène Amieva, Sylvaine Artero, et al.. Subjective memory impairment, objective cognitive functioning and social activity in French older people: findings from the Three Cities study.. Geriatrics and Gerontology International, 2013, 13 (1), pp.139-45. 10.1111/j.1447-0594.2012.00873.x . inserm-00914850

\section{HAL Id: inserm-00914850 https://www.hal.inserm.fr/inserm-00914850}

Submitted on 6 Dec 2013

HAL is a multi-disciplinary open access archive for the deposit and dissemination of scientific research documents, whether they are published or not. The documents may come from teaching and research institutions in France or abroad, or from public or private research centers.
L'archive ouverte pluridisciplinaire HAL, est destinée au dépôt et à la diffusion de documents scientifiques de niveau recherche, publiés ou non, émanant des établissements d'enseignement et de recherche français ou étrangers, des laboratoires publics ou privés. 
Subjective memory impairment, objective cognitive functioning and social activity in French older people: Findings from the 3C study

Mirella Genziani, ${ }^{1}$ Robert Stewart ${ }^{1,2}$, Yannick Béjot ${ }^{3}$, Hélène Amieva ${ }^{4}$, Sylvaine Artero $^{2,}$, Karen Ritchie 2,5

1. Institute of Psychiatry, King's College, London ;

2. Inserm, U1061 Neuropsychiatry,, Montpellier, France ; Université Montpellier I, Montpellier ;

3. Yannick Béjot, Centre Mémoire Ressources Recherche, CHU Dijon;

4. Inserm, U593, Bordeaux, F-33076 France ;

5. Faculty of Medicine, Imperial College, London, UK

Text word count : 2,357

Key words: subjective memory impairment, cognitive function, social activity, older people 


\section{Abstract}

Objectives: To investigate the association between subjective memory impairment (SMI) and objective cognitive impairment in later life, and to ascertain whether this is modified by level of social activity, education or living alone. Design and Setting: Data were analysed from three French community surveys carried out in Bordeaux, Dijon and Montpellier.

Participants: Representative samples of 9294 residents aged 65 years and over.

Measurements: SMI was ascertained and investigated in relation to performance on the Benton Visual Retention Test (BVRT), the Isaac Set Test (IST) and Trail Making Test B (TMT). Adjustments were made for age, sex, education, depressive symptoms (CES-D), site and living alone. Stratified analyses investigated modification by high or low social activity, education or living arrangement.

Results: SMI was reported by $21.9 \%$ of the sample and was significantly associated with lower scores on BVRT and TMT after adjustment for age, sex, education, depressive symptoms, site and living alone. These associations were not significantly modified by social activity, education or living alone.

Conclusions: Worse subjective memory was associated independently with worse performance on two tests of cognitive function but, in these cohorts, no evidence was found for modification of associations by social activity/support or education. 


\section{Introduction}

Subjective memory impairment (SMI) is one of the core components of the diagnostic criteria for Mild Cognitive Impairment $(\mathrm{MCl})$ and a key potential presenting symptom stimulating referral to secondary assessment services such as memory clinics. ${ }^{(1,2)}$ Subjective memory complaint concerns an individual's awareness, self-appraisal and beliefs about their everyday memory competence. Reported common concerns have included misplacing items and forgetting new information. ${ }^{(3-5)}$ A number of studies have found a higher prevalence of SMI among populations over the age of $65 .{ }^{(6,7)}$ However, associations with objective cognitive impairment have been somewhat inconsistent, ${ }^{(8)}$ with some studies, ${ }^{(7-9)}$ but not others, ${ }^{(10)}$ finding associations with impaired performance. Depression, on the other hand, is almost invariably strongly associated with SMI. ${ }^{(6,11)}$

The influence of social activity and environmental cognitive demands on the association between SMI and objective cognitive functioning is less clear, although it has been reported that increased social activity slows cognitive decline and is associated with cognitive plasticity in later life. ${ }^{(12)}$ Activities such as learning languages, playing games or a musical instrument provide substantial cognitive stimulation, which is enhanced by social environment. ${ }^{(11,12)}$ As well as potentially buffering against cognitive decline, more demanding environments may also increase the likelihood of someone noticing early cognitive deficits - i.e. can be hypothesised to modify (strengthen) the association between subjective and objective memory impairment. Supporting this, in one community study a stronger association was found between SMI and objective cognitive impairment 
in older people living in an urban compared to a rural area, and this association was strongest of all in elders who had migrated from a rural to an urban area compared to those with lifelong urban residence. ${ }^{(13)}$ Furthermore, within an urban sample, the strength of association between SMI and objective cognitive impairment was higher in individuals with higher levels of social support - again, potentially a marker of a more cognitively demanding lifestyle. ${ }^{(14)}$

Through an analysis of data from a large community study of French older people, we sought to investigate the association between SMI and objective cognitive impairment, and the extent to which this was modified by three preidentified factors: living alone, level of education and level of social activity. 


\section{Methods}

\section{Setting and sample}

The 3-Cities (3C) study is a multi-centre population-based cohort study of community residents aged 65 and older, conducted in the three French cities of Montpellier (South East), Dijon (North East) and Bordeaux (South West). At baseline in 1999-2000, the recruited cohort included 9,294 participants $(3,718$ men and 5,576 women; 2,104 in Bordeaux, 4,931 in Dijon, and 2,259 in Montpellier), taking into account participants who refused to partake in the baseline medical interview ( $n=392,4 \%)$, who were excluded from all analyses. The Ethics Committee of the University Hospital of Kremlin-Bicêtre, France approved the $3 \mathrm{C}$ study. The study protocol has been described in detail in previous publications. ${ }^{(3,15,16)}$

\section{Measures}

The following socio-demographic data were considered as covariates in this analysis: age, sex, education level (2 categories of duration of formal education: $<5$ years or $5+$ years), living alone or not, and case-level depressive symptoms defined by the Centre for Epidemiological Depression (CES-D) scale (applying the standard score cut-off of 16 and above to denote the presence of case level depressive symptoms). ${ }^{(17)}$

Subjective memory impairment, the principal dependent variable, was assessed using a self-report questionnaire applied to all 3C study participants. ${ }^{(3)}$ Participants were asked about habitual forgetfulness during daily activities, and 
about difficulties remembering new information. Participants who responded positively to both these questions were categorised as having SMI and compared with the remainder of the sample. This definition of SMI has been applied in previous research. ${ }^{(16)}$

The following measures of cognitive function were treated as the principal independent variables: a) Benton Visual Retention Test (BVRT), which tests immediate visual recall ${ }^{(18,19)}$ b) the Isaac Set Test (IST), which tests cued semantic access ${ }^{(20)}$ and c) The Trail Making Test (TMT), part B - a test of attention and task shifting, requiring the participant to connect a series of alternative numbers and letters. ${ }^{(21,22)}$ For this analysis, the three measures were re-categorised into binary variables, relative impairment being defined using standard cut-offs for the BVRT and IST ( $<13$ and $<25$ respectively) and $75^{\text {th }}$ percentile or above for time taken to complete the TMT. These definitions have been applied in previous research, ${ }^{(16)}$ and the instruments had been previously validated for use with a community population and translated in a number of languages, including French. ${ }^{(18,22,23)}$

Social activity was measured at baseline using a self-report frequency activities questionnaire and its second section which focuses on activities that are more often carried out with other people rather than in isolation. ${ }^{(3,24)}$ Questions included items asking about social contact with other people, such as friends and family members, and whether participants had pursued any leisure, social or cultural activities. For the purpose of this analysis from a scale with a total maximum score of 33 , high/low social activity was re-categorised into a binary 
variable based on scores above or below the median score of 14 . This measure was investigated as a potential effect modifier in this analysis.

\section{Statistical analysis}

SPSS version 15.0 was used. ${ }^{(25)}$ SMI was modelled as the principal (binary) dependent variable and descriptive data were generated on its prevalence and unadjusted associations with potential covariates. SPSS syntax commands were compiled in manner to facilitate the exclusion of cases with a diagnosis of dementia, since the objective of the analysis was to examine cognitively healthy individuals, residing in the community. Logistic regression models were used to sequentially adjust for age, gender, education, case-level depressive symptoms, city, and living alone. Associations were finally stratified by the three proposed effect modifiers: living alone or not, above/below median social activity and high/low education, using Mantel-Haenszel procedures ${ }^{(26)}$ with tests of homogeneity to investigate modification. 


\section{Results}

The analysed baseline sample consisted of 9,294 participants. The mean age was $74.3 ; 60.7 \%$ were female and $26.1 \%$ had low education. The observed prevalence of SMI was $21.9 \%$. As displayed in Table 1, SMI was significantly associated with older age, female sex, lower education, social activity and caselevel depressive symptoms.

Associations between covariates and cognitive impairment on the three tests are summarised in Table 2. Increased age was associated with impairment on the BVRT but not on the other two tests. Impairment on the IST was more common in men but impairment on the other two tests was more common in women. Impairment on all three tests was more common in participants with lower education, in those who were widowed, and in those with case-level depression. Although significant differences were found between sites for all three impairment definitions, these did not follow a consistent pattern; neither did associations with living alone or not. Impairment on all three tests was significantly more likely in participants reporting SMI.

In logistic regression analyses (Table 3), SMI remained significantly associated with impairment on the BVRT and TMT after sequential adjustment by all covariates. The association between SMI and impairment on the IST remained significant after adjustment for age, sex and education level, but was reduced substantially in strength after adjustment for depressive symptoms. Education and depressive symptoms were the strongest potential confounders with largest 
effects of adjustment on the associations of interest. In stratified analyses, the associations of interest did not differ substantially, consistently or significantly between social activity, living status or education groups (Table 3). 


\section{Discussion}

The principal findings from this secondary analysis were strong cross-sectional associations between SMI and objective cognitive impairment in tests of delayed recall (BVRT) and executive function / psychomotor speed (TMT). These associations persisted after adjustment for potential confounding factors but, contrary to expectations, were not modified by social activity, education or whether participants were living alone. Associations between subjective and objective cognitive impairment are consistent with findings from some previous research. ${ }^{(7,16)}$ Education level and depressive symptoms showed the greatest potential confounding effects and the latter had a pronounced impact on the association between SMI and verbal fluency (IST) impairment. These findings are in keeping with other studies which highlighted the importance of depressive symptoms and education level as potential confounding factors, ${ }^{(7,27)}$ although these did not fully account for the associations between SMI and the two other measures of cognitive impairment.

There was no evidence in this sample of effect modification by social activity, living circumstances or education, hypothesised to reflect cognitive activity in these samples. This finding is not therefore consistent with the effect modification described for social support with respect to inner London older residents, ${ }^{(14)}$ or urban environment for Korean elders. ${ }^{(13)}$ More research is required to investigate this issue as it is reasonable to suppose that an individual's recognition of early cognitive dysfunction is likely to be influenced at least to some extent by their environmental context and that people in circumstances presenting higher levels 
of cognitive challenge may notice dysfunction at an earlier stage. The associations between cognitive impairment and SMI in this sample suggest that individuals both notice and are willing to report cognitive difficulties. One possibility for the lack of effect modification may be that the measures chosen in this sample did not sufficiently reflect environmental cognitive challenge, which may vary between settings and cultures. ${ }^{(28)}$

An interesting finding was that SMI was associated with impairment not only on a test of recall (BVRT) but also on Trail Making Test B which principally tests psychomotor speed and executive function. Although impairment in executive functioning is associated with onset of dementia, it is less often considered in the routine clinical appraisal of age-related cognitive functioning. Deficits in executive functioning and attentional mechanisms may be appraised as forgetfulness by older people, because memory lapses are considered to be part of normal age related cognitive change, or it may simply reflect the lack of an alternative word to reflect the experience of impairment in other domains. ${ }^{(11)}$

Difficulties with attention give rise to memory difficulties through failure to allocate attentional resources to relevant stimuli. This may also reflect the role of executive functioning in memory for everyday tasks - particularly, the ability to switch tasks or 'multi-task' and with learning. ${ }^{(22)}$

In terms of methodological considerations, the $3 \mathrm{C}$ study dataset presented a valuable opportunity for investigating these research questions, involving community-based samples with sufficient statistical power to detect a range of associations. ${ }^{(3)}$ The findings on the association between SMI and objective 
cognitive impairment therefore add to the existing literature. ${ }^{(7,11,14,29,30)}$ Although it is likely that objective cognitive impairment plays a causal role in the likelihood of someone reporting SMI, the cross-sectional nature of the study does not allow this inference to be drawn. There were some limitations in the relatively brief measures of SMI and a construct such as social activity. Cognitive assessment in the samples was also limited to the three tests presented here and did not include, for example, any assessment of verbal memory.

SMI and its association with objective cognitive impairment have been evaluated previously. ${ }^{(8,16)}$ The relationship between SMI and objective memory impairment in older adults is likely to reflect a complex interaction of bio-psychosocial factors. $(3,14,16)$ Findings of associations between the two have implications at clinical, service and policy levels. Given the increasing prevalence of dementia with population aging, memory clinics for detection, prevention and intervention programmes are being prioritised in France. ${ }^{(31)}$ Since SMI is one of the few means by which early cognitive dysfunction may come to the attention of such services, further research is required to examine the meaning and implications of the construct, as well as devising better ways to define it. ${ }^{(2)}$ 


\section{Acknowledgements}

The authors would like to thank the following people: a) Participants who provided data for the $3 \mathrm{C}$ Study; b) The research team of the $3 \mathrm{C}$ study within Institut National de la Santé et de la Recherche Médicale (INSERM) and the healthcare staff involved in the management, recruitment, collection of data. RS is funded by the NIHR Specialist Biomedical Research Centre for Mental Health at the South London and Maudsley NHS Foundation Trust and Institute of Psychiatry, King's College London.

The 3C Study is conducted under a partnership agreement between Inserm, the Victor Segalen - Bordeaux II University and Sanofi-Synthélabo. The Fondation pour la Recherche Médicale funded the preparation and first phase of the study. The 3C-Study is also supported by the Caisse Nationale Maladie des Travailleurs Salariés, Direction Générale de la Santé, MGEN, the Institut de la Longévité, Agence Française de Sécurité Sanitaire des Produits de Santé, the Regional Governments of Aquitaine, Bourgogne and Languedoc-Roussillon and, the Fondation de France, the Ministry of Research-Inserm Programme 'Cohorts and collection of biological material'. The Lille Génopôle received an unconditional grant from Eisai. 


\section{References}

(1) Dartigues JF, Helmer C, Peres K, Cowppli-Bony P, Auriacombe S, Orgogozo JM. Early prevention at public health issue. Journal of Nutrition Health \& Aging 2008;12(1):84S-85S.

(2) Ritchie K, \&, Touchon J. Mild cognitive impairment: conceptual basis and current nosological status. Lancet 2000;355:225-228.

(3) 3C Study Group. Vascular factors and risk of dementia: design of the ThreeCity study and baseline characteristics of the study population. Neuroepidemiology 2003;22:316-325.

(4) Mitchell A. The clinical significance of subjective memory complaints in the diagnosis of mild cognitive impairment and dementia: a meta-analysis. Int.J.Geriatr.Psychiatry 2008;23:1191-1202.

(5) EM Z, MJ G. Assessment of memory complaints by rating scales and questionnaires. Psychopharmacol.Bull. 1988;24(4):523-529.

(6) Christensen H, Jorm AF, Henderson AS, Mackinnon AJ, Korten AE, Scott LR. The relationship between health and cognitive functioning in a sample of elderly people in the community. Age Ageing 1994;23(3):204-212.

(7) Gagnon M, Francoise Dartigues J, Mazaux J, Dequae L, Letenneur L, Giroire $J$, et al. Self-reported memory complaints and memory performance in elderly French community residents: Results of the PAQUID Research programme. Neuroepidemiology 1994;13:145-154.

(8) Schofield P. Association of subjective memory complaints with subsequent cognitive decline in community-dwelling elderly individuals with baseline cognitive impairment. 2009.

(9) Jonker C, MI G, B S. Are memory complaints predictive for dementia? A review of clinical and population-based studies. Int J GeriatrPsychiatry. 2000;15(11):983-991.

(10) Harwood D, Barker W, Ownby R, al e. No association between subjective memory complaints and apoliprotein $\mathrm{E}$ genotype in cognitively intact elderly. Int.J.Geriatr.Psychiatry 2004;19:1131-1139.

(11) Anstey KJ, \&, Low LF. Normal cognitive changes in aging. Aust.Fam.Physician 2004;33(10):783-787.

(12) Lee Y, Kim J, Back J. The influence of multiple lifestyle behaviours on cognitive function in older persons living in the community. Prev.Med. 2009;48:86-90. 
(13) Kim J, Stewart R, Shin I, Choi S, Yoon J. Subjective Memory Impairment, cognitive function and depression: A community study in older Koreans.

Dement.Geriatr.Cogn.Disord. 2003;15:218-225.

(14) Trouton A, R S, Prince M. Does social activity influence the accuracy of subjective memory deficit? Findings from a British community survey. Journal of American Geriatric Society 2006;54(7):1108-1113.

(15) Portet F, Artero S, Kotski P, Ritchie K, Touchon J. Five-year longitudinal study of elderly subjects with memory complaints: The interest of SPECT. Neurology 2001;56(8):A262-A263.

(16) R S, C D, Godin O, Ritchie K, Maillard P, Delcroix N, et al. Neuroimaging correlates of subjective memory deficits in a community population. Neurology 2008;70:1601-1607.

(17) Radloff LS. The CES-D Scale: A Self Report Depression Scale for Research in the General. Applied psychological measurement 1977;1(3):385-401.

(18) Benton A. Manuel pour l'application du test de rétention visuelle.

Applications cliniques et expérimentales. Centre de Psychologie Appliquée 1965.

(19) Campo P, Morales M. Reliability and normative data for the Benton Visual Form Discrimination Test. Clin.Neuropsychol. 2003;17(2):220-225.

(20) Isaac B, Kennie A. The set test as an aid to the detection of dementia in old people. Br.J.Psychiatry 1973;45:957-962.

(21) Giovagnoli A, Del Pesce M, Mascheroni S, al e. Trail Making Test: normative values from 287 normal adult controls. Ital.J.Neurol.Sci. 1996;17:305-309.

(22) Lezak M, Howieson B, Loring D, al e. Neuropsychological Assessment. 2004.

(23) Isaacs B, Kennie AT. Set Test As An Aid to Detection of Dementia in Old People. Br.J.Psychiatry 1973;123(575):467-470.

(24) Isaac V, Stewart R, Ancelin M, Artero S, \&, Ritchie K. Social activity and improvement in depressive symptoms in the elderly: a prospective community cohort study. submitted 2009.

(25) Inc S. SPSS 15.0 Command Syntax Reference. 2003.

(26) Prince M, R S, Ford T, Hotopf M. Practical psychiatric epidemiology. ; 2007.

(27) Jorm A, Christensen H, Korten A, Henderson A, Jacomb P, Mackinnon A. Do cognitive complaints either predict future cognitive decline or reflect past cognitive decline? A longitudinal study of an elderly community sample.

Psychol.Med. 1997;27:91-98. 
(28) Kim JM, Stewart R, Kim SW, Yang SJ, Shin IS, Yoon JS. A prospective study of changes in subjective memory complaints and onset of dementia in South Korea. American Journal of Geriatric Psych 2006;14(11):949.

(29) Stewart R, Russ C, Richards M, B,C, Lovestone S, Mann A. Depression, Apoe $E$ genotype and subjective memory impairment: A cross-sectional study in an African-Caribbean population. Psychol.Med. 2001;31:431-440.

(30) Dufouil C, Fuhrer R, Alperovitch A. Subjective cognitive complaints and cognitive decline: consequence or predictor? The epidemiology of vascular aging study. Journal of American Geriatric Society 2005;53:616-621.

(31) Europe A. Déclaration de Paris : priorités politiques du mouvement Alzheimer en Europe: Note de synthèse. 2007:1-7. 
Table 1: Associations between sample characteristics and subjective memory impairment (SMI)

\begin{tabular}{llll}
\hline Covariates & Number of & $\%$ SMI & $\chi^{2}$ Value $(\mathrm{df})^{\dagger}$ Pearson Chi- \\
participants & $(\mathrm{N})$ & Square, degrees of Freedom \\
& & $p$-value
\end{tabular}

\section{Age}

$<75$ years

5026

4069

$>75$ years

Sex

Male

Female

\section{Education duration}

Less than 5 years

5 years or more

Depressive symptoms*

Non-case (CES-D <16)

Case (CES-D 16+)

City

Bordeaux

Dijon

Montpellier

Living Alone

Yes

3247

No
1244

5588

3488

7720

19.5 (1508)

154.90 (1) $p<0.001$

$35.2(438)$
24.7 (1378) $65.12(1) p<0.001$

$17.5(609)$
$35.15(1) p<0.001$

$24.7(1007)$

$19.9(712) \quad 13.80(1) p<0.001$

$23.2(1279)$ 
${ }^{\dagger}$ Pearson Chi-square, (degrees of freedom)

${ }^{*}$ CES-D $=$ Centre for Epidemiologic Studies Depression Scale 
Table 2: Unadjusted associations between covariates and objective cognitive impairment

Covariates
Proportion with cognitive impairment

$\%$ Benton Visual

Retention Rest

(N)
$\%$ Trail Making test

B

(N)

\begin{tabular}{|c|c|c|c|}
\hline \multicolumn{4}{|l|}{ Age } \\
\hline$<75$ years & $27.8(1395)$ & 33.5 (1297) & $24.9(1208)$ \\
\hline$>75$ years & $29.1(1137)$ & 36.5 (1839) & $25.1(908)$ \\
\hline Chi-square (df), p-value & 1.64 (1) $p=0.200$ & $8.42(1) p=0.004$ & 0.03 (1) $p=0.855$ \\
\hline \multicolumn{4}{|l|}{ Sex } \\
\hline Male & $30.8(1080)$ & $30.4(1064)$ & $23.6(788)$ \\
\hline Female & $26.8(1452)$ & $38.3(2072)$ & $25.9(1328)$ \\
\hline Chi-square (df), p-value & 17.30 (1) $p<0.001$ & 58.40 (1) $p<0.001$ & 5.90 (1) $p=0.015$ \\
\hline \multicolumn{4}{|l|}{ Education duration } \\
\hline Less than 5 years & $31.2(1708)$ & 40.7 (2219) & $29.0(1478)$ \\
\hline 5 years or more & 23.7 (816) & $26.4(909)$ & $18.8(632)$ \\
\hline Chi-square (df), $p$-value & 59.92 (1) $p<0.001$ & 190.59 (1) $p<0.001$ & $112.84(1) p<0.001$ \\
\hline \multicolumn{4}{|l|}{ Depressive symptoms* } \\
\hline Non-case (CES-D <16) & $27.0(2056)$ & $34.2(2595)$ & $24.1(1752)$ \\
\hline Case (CES-D 16+) & $35.4(430)$ & $40.7(490)$ & $29.7(332)$ \\
\hline Chi-square (df), p-value & 35.90 (1) $p<0.001$ & 19.49 (1) $p<0.001$ & 16.10 (1) $p<0.001$ \\
\hline \multicolumn{4}{|l|}{ City } \\
\hline Bordeaux & $37.6(740)$ & $35.6(697)$ & $32.4(571)$ \\
\hline Dijon & $20.8(1002)$ & $38.0(1817)$ & $25.0(1159)$ \\
\hline Montpellier & $37.0(790)$ & 28.7 (622) & $18.7(386)$ \\
\hline Chi-square (df), p-value & $298.73(2) p<0.001$ & $57.15(2) p<0.001$ & 95.95 (2) $p<0.001$ \\
\hline
\end{tabular}




\section{Living Alone}

Yes

No

Chi-square (df), p-value

\section{Social Activity}

High

Low

Chi-square (df), p-value

SMI

Present

Not Present

Chi-square (df), p-value
$28.2(1612)$

$28.8(918)$

0.33 (1) $p=0.567$

$16.6(175)$

$25.8(1217)$

40.48 (1) $p<0.001$

$30.8(577)$

27.7 (1902)

7.06 (1) $p=0.008$
33.8 (1929)

$37.8(1198)$

14.30 (1) $p<0.001$

$27.1(286)$

$35.2(1658)$

25.29 (1) $p<0.001$

$40.1(751)$

33.9 (2324)

25.06 (1) $p<0.001$
$26.4(783)$

$24.2(1328)$

4.87 (1) $p=0.027$

$14.5(151)$

23.1 (1049)

37.68 (1) $p<0.001$

30.9 (548)

$23.3(1521)$

42.93 (1) $p<0.001$

${ }^{*} \mathrm{CES}-\mathrm{D}=$ Centre for Epidemiologic Studies Depression Scale 
Table 3: Logistic regression analysis of the association (odds ratio) between subjective memory impairment (SMI) and cognitive impairment on the three component tests

Logistic regression Association between test-specific cognitive impairment and SMI
model (odds ratio, $95 \% \mathrm{Cl}$ )

Isaac test

Benton test

Trail B test

1. Unadjusted

2. Adjusted for age

3. Model 2 plus sex

$1.16(1.04-1.31)$

$1.30(1.17-1.45)$

$1.25(1.12-1.39)$

4. Model 3 plus

$1.14(1.02-1.27)$

education

5. Model 4 plus

$1.08(0.96-1.21)$

depressive symptoms

6. Model 5 plus city

$1.08(0.96-1.21)$

7. Model 6 plus living

$1.08(0.96-1.21)$

alone

Stratified analyses*

Social activity

High

$0.92(0.60-1.43)$

$1.31(1.17-1.45)$

$1.32(1.20-1.47)$

$1.47(1.31-1.65)$

$1.46(1.30-1.65)$

$1.42(1.26-1.60)$

$1.22(1.09-1.36)$

$1.40(1.24-1.57)$

$1.21(1.08-1.35)$

$1.37(1.22-1.54)$

Low

$\mathrm{p}$-value for interaction
$1.10(0.94-1.28)$

$p=0.038$
1.19 (0.84-1.69)

$1.28(1.11-1.47)$

$p=0.520$
$1.91(1.27-2.86)$

$1.53(1.31-1.80)$

$\mathrm{p}=0.257$ 


\section{Living Alone}

Yes

No

$p$-value for interaction

Education duration

Less than 5 years

$1.11(0.97-1.27)$

$1.14(0.93-1.40)$

$p=0.841$

$\mathrm{p}=0.377$
$1.41(1.19-1.68)$

$1.25(1.09-1.43)$

$p=0.274$

$\mathrm{p}=0.718$
$1.51(1.25-1.83)$

$1.45(1.25-1.68)$

$1.28(1.13-1.46)$

$1.40(1.22-1.60)$

$1.11(0.91-1.37)$

$\mathrm{p}=0.242$
$1.41(1.13-1.80)$

$\mathrm{p}=0.919$

*Unadjusted odds ratios 